\title{
Unclear Abdominal Discomfort: Pivotal Role of Carbohydrate Malabsorption
}

\author{
Miriam Goebel-Stengel, ${ }^{1 *}$ Andreas Stengel, ${ }^{2}$ Marco Schmidtmann, ${ }^{1}$ Ivo van der Voort, ${ }^{1}$ Peter Kobelt ${ }^{2}$ and Hubert Mönnikes ${ }^{1}$ \\ ${ }^{1}$ Department of Internal Medicine, Institute of Neurogastroenterology and Motility, Martin-Luther Hospital, Academic Teaching Institution of \\ Charité - University Medical Center, Berlin, Germany; and ${ }^{2}$ Charité Center for Internal Medicine and Dermatology, Division of General Internal \\ and Psychosomatic Medicine; Charité-Universitätsmedizin Berlin, Campus Benjamin Franklin, Berlin, Germany
}

\begin{abstract}
Background/Aims
Carbohydrate malabsorption is frequent in patients with functional gastrointestinal disorders and in healthy volunteers and can cause gastrointestinal symptoms mimicking irritable bowel syndrome (IBS). The aim of this study was to investigate the prevalence of symptomatic lactose and fructose malabsorption in a large population of patients with IBS-like symptoms based on Rome II criteria.
\end{abstract}

\section{Methods}

Patients with unclear abdominal discomfort $(n=2,390)$ underwent lactose $(50 \mathrm{~g})$ and fructose $(50 \mathrm{~g})$ hydrogen $\left(\mathrm{H}_{2}\right)$ breath tests and depending on the results further testing with $25 \mathrm{~g}$ fructose or $50 \mathrm{~g}$ glucose, or upper endoscopy with duodenal biopsies. Additionally, this population was investigated regarding the prevalence of small intestinal bacterial overgrowth (SIBO) based on glucose breath test and celiac disease.

Results

Of the 2,390 patients with IBS-like symptoms, 848 (35\%) were symptomatic lactose malabsorbers and 1,531 (64\%) symptomatic fructose malabsorbers. A combined symptomatic carbohydrate malabsorption was found in $587(25 \%)$ patients. Severe fructose malabsorbers (pathologic $25 \mathrm{~g}$ fructose test) exhaled significantly higher $\mathrm{H}_{2}$ concentrations in the $50 \mathrm{~g}$ test than patients with negative $25 \mathrm{~g}$ fructose test $(P<0.001)$. Out of $460 / 659$ patients with early significant $\mathrm{H}_{2}$ increase in the lactose and fructose test who underwent a glucose breath test, 88 patients had positive results indicative of SIBO and they were significantly older than patients with negative test result $(P<0.01)$. Celiac disease was found in $1 / 161$ patients by upper endoscopy.

\section{Conclusions}

Carbohydrate malabsorption is a frequent but underestimated condition in patients with IBS-like symptoms although diagnosis can be easily confirmed by $\mathrm{H}_{2}$ breath testing.

\section{(J Neurogastroenterol Motil 2014;20:228-235)}

Key Words

Breath tests; Fructose; Hydrogen; Irritable bowel syndrome; Lactose

Received: November 19, 2013 Revised: February 26, 2014 Accepted: February 27, 2014

(c) This is an Open Access article distributed under the terms of the Creative Commons Attribution Non-Commercial License (http://creativecommons. org/licenses/by-nc/3.0) which permits unrestricted non-commercial use, distribution, and reproduction in any medium, provided the original work is properly cited.

*Correspondence: Miriam Goebel-Stengel, MD, PhD

Department of Internal Medicine, Institute of Neurogastroenterology and Motility, Martin-Luther Krankenhaus, Caspar-They $\beta$-Str. 27-31, 14193 Berlin, Germany.

Tel: +49-30-8955-3111, Fax: +49-30-8955-4554, E-mail: miriam.goebel-stengel@gmx.de

Financial support: This work was supported by DFG Grant Mö 458/4-3 and Charité Grant UFF 2005-55.

Conflicts of interest: None.

Author contributions: Miriam Goebel-Stengel conducted the study, collected and interpreted data and drafted the manuscript; Andreas Stengel conducted the study, collected and interpreted data; Marco Schmidtmann conducted the study, collected and interpreted data; Ivo van der Voort conducted the study and collected data and reviewed the manuscript; Peter Kobelt conducted the study and collected data; Hubert Mönnikes planned the study, interpreted data and reviewed the manuscript. 


\section{Introduction}

Recurrent or chronic abdominal discomfort is a common condition in the health care setting. Most patients have had prior medical evaluation that did not yield a satisfactory diagnosis. Common organic causes of chronic abdominal pain and discomfort encompass peptic ulcer disease, postoperative adhesive bands or gynaecologic disorders. However, the irritable bowel syndrome (IBS) and carbohydrate malabsorption are also frequent in patients with unexplained gastrointestinal symptoms.

Lactose, a disaccharide composed of galactose and glucose, is cleaved into absorbable monosaccharides by the enzyme lactase which is found in the epithelium of the small intestine. Lactose intolerance results from a lack of lactase often referred to as lactase deficiency. ${ }^{1}$ The non-digested lactose cannot be absorbed in the small intestine and thus reaches the colon. For the monosaccharide fructose, the glucose transporter (GLUT)-5 protein of the enterocytes is the preferred transport system out of the small intestinal lumen. ${ }^{2}$ A lack of this transporter and/or a shortened small intestinal transit time result in an exceeding transport capacity for fructose. ${ }^{3,4}$

At their onward transport, fructose and lactose that remain in the lumen of the small intestine subsequently reach the colon and are fermented by resident bacteria. ${ }^{5-7}$ Degradation products of the bacterial metabolism are hydrogen $\left(\mathrm{H}_{2}\right)$, carbon dioxide, hydrogen sulfide, methane and short chain fatty acids. ${ }^{5,6,8}$ While hydrogen is partly absorbed and exhaled and does not lead to osmotic diarrhea which is caused by short chain fatty acids and undigested oligodisaccharides, ${ }^{5-7}$ it may, similar to other gaseous metabolites, cause bloating and abdominal distension resulting in abdominal discomfort and cramps, especially in individuals with visceral hypersensitivity. Altogether, these symptoms can imitate IBS. ${ }^{9,10}$

Hydrogen breath tests offer an excellent non-invasive method to detect excessive production of hydrogen as seen in fructose and lactose malabsorption. The disability to sufficiently cleave lactose accompanied by clinical symptoms is referred to as symptomatic lactose malabsorption while the lack of clinical symptoms is referred to as lactose malabsorption. After infancy, most mammals, including humans, lose the intestinal enzyme lactase and thus the ability to digest lactose. ${ }^{11}$ Due to a genetic mutation, others keep the ability and worldwide, the persistence of the lactase gene is the most common enzymatic variant. Interestingly, this highly penetrant autosomal-dominant genetic polymorphism obeys a characteristic geographic distribution increasing from North to
South, which is underlined by data showing that in Scandinavian countries only $3-8 \%$ of the population lack lactase, ${ }^{12}$ while the prevalence in the Austrian study group is around $20 \%,{ }^{13}$ in China about $28 \%,{ }^{14}$ in the Mediterranean up to $70 \%$ and in equatorial Africa even up to $98 \% .{ }^{15}$ One has to consider that due to migration the number of people experiencing nutritional problems due to lactase deficiency in Europe steadily increases.

Lactose malabsorption has already been well recognized as a cause of non-specific gastrointestinal (GI) symptoms. ${ }^{16-18}$ On the contrary, malabsorption of fructose is less well studied but has recently received growing attention through the fact that restricting rapidly fermentable oligo-, di- and monosaccharides and polyols (FODMAPs) is beneficial in controlling symptoms of abdominal discomfort. ${ }^{19,20}$ Indeed, 2 studies reported a prevalence of fructose malabsorption in functional dyspepsia or unexplained GI symptoms of $40-55 \%$ and $73 \%$, respectively. ${ }^{10,18}$ Therefore, it seems to be reasonable to perform routine fructose $\mathrm{H}_{2}$ breath tests in patients with unexplained abdominal symptoms who have had an unremarkable medical check-up including laboratory tests, physical examination, ultrasound and endoscopy and in the absence of "red flags" (e.g., unintended weight loss, rectal bleeding, fever, severe diarrhea or vomiting, persistent pain in the upper or lower right abdomen, family history of inflammatory bowel disease or colon cancer).

The gold standard to detect small intestinal bacterial overgrowth (SIBO) is the culture of jejunal aspirates. However, in clinical practice the $\mathrm{H}_{2}$ breath test with glucose is often preferred. ${ }^{4}$ In healthy subjects, glucose is completely absorbed in the proximal small intestine, while in SIBO glucose is fermented by bacteria before absorption resulting in an early or late rise of $\mathrm{H}_{2}$ levels from the dysbiosis of the jejunum or ileum, respectively.

Up to now there is a lack of studies describing the role of carbohydrate malabsorption in patients with IBS-like symptoms in large study populations. Therefore, in a retrospective analysis, we characterized 2,390 patients with unclear abdominal discomfort with regards to occurrence, prevalence and severity of carbohydrate malabsorption, SIBO and celiac disease which may also lead to abdominal discomfort and IBS-like symptoms.

\section{Materials and Methods}

\section{Patient Population Characteristics}

The documentation and archive system of the gastroenterological unit of the Charité Medical Center has been used as 
study entry database. Patients were outpatients or admitted from other departments of the Charité Medical Center for hydrogen breath testing due to their GI symptoms in the years from 2000 to 2006. All patients consented to their data analysis for study purpose. They were asked about GI infections, antibiotics use or colonoscopy within the last 4-6 weeks. The breath tests were only performed 4-6 weeks after such an event. All subjects who presented with unclear abdominal discomfort (e.g., IBS-like symptoms) had unremarkable physical examination, lab results, ultrasound and endoscopy in the absence of "red flags" (e.g., unintended weight loss, rectal bleeding, fever, family history of inflammatory bowel disease and colon cancer, persistent pain in the upper or lower right abdomen, severe diarrhea or vomiting). All subjects who had taken $2 \mathrm{H}_{2}$ breath tests, with $50 \mathrm{~g}$ lactose and fructose, respectively, were included $(n=2,390)$.

Abdominal IBS-like symptoms were assessed once at the first contact with patient by a GI symptom questionnaire that is routinely used by the outpatient clinic at the Charité Medical Center for functional GI and motility disorders. This questionnaire has not been validated yet but was used before ${ }^{21}$ and can group patients according to Rome II criteria.

\section{Hydrogen Breath Test}

The $\mathrm{H}_{2}$ breath tests all followed the same regimen. After an 18-hour overnight fast (water only), an end-expiratory breath sample was collected from the patients into a syringe. The breath sample was immediately analyzed by the use of a GMI Exhaled Hydrogen Monitor (GMI Medical, Renfrew, UK; measurement range $0-250$ parts per million [ppm], sensitivity $2 \mathrm{ppm}$, measurement accuracy $\pm 2 \%, \pm 1 \mathrm{ppm}$ for values $<50 \mathrm{ppm}$ ) and the result of the measurement was documented. First, 2 baseline values for $\mathrm{H}_{2}$ were determined in the end-expiratory exhalation air. Only patients who showed a starting value of $\leq 20 \mathrm{ppm}$ were included. After an oral load of the relevant carbohydrate in 200 $\mathrm{mL}$ water, according to the current German guidelines, ${ }^{4}$ further breath samples were obtained every 10 minutes over the measurement period of 180 minutes. An increase of the end-expiratory $\mathrm{H}_{2}$ concentration $>20 \mathrm{ppm}$ above average baseline within 180 minutes was defined as significant/pathologic rise. The time until the first significantly increased value, time and value of the maximum $\mathrm{H}_{2}$ concentration as well as the concurrent abdominal symptoms under the carbohydrate load were documented.

\section{Definitions and Measurements}

\section{Lactose hydrogen breath test}

Patients received a solution consisting of $50 \mathrm{~g}$ lactose in 200 $\mathrm{mL}$ water. $\mathrm{An}_{2}$ increase without typical abdominal symptoms was defined as lactose malabsorption. Patients with a pathologic $\mathrm{H}_{2}$ increase in combination with abdominal symptoms were defined as symptomatic lactose malabsorbers.

\section{Fructose hydrogen breath test}

The German guideline on clinically relevant breath tests in gastroenterology recommends the performance of hydrogen breath tests with $50 \mathrm{~g}$ fructose (in $200 \mathrm{~mL}$ water) first and an additional test with $25 \mathrm{~g}$ fructose (in $100 \mathrm{~mL}$ water) in case of a positive result to rule out fructose malabsorption. ${ }^{4}$ The term fructose intolerance describes a genetic disorder (deficiency of aldolase $B$ due to ALDOB gene mutation). Analogous to lactose indigestion, we use the term fructose malabsorption to describe intestinal fructose malabsorption expressed by an $\mathrm{H}_{2}$ increase without corresponding symptoms and symptomatic fructose malabsorption for patients who present with symptoms in addition to their malabsorption. Patients with a pathologic $\mathrm{H}_{2}$ breath test with $50 \mathrm{~g}$ fructose and a normal $\mathrm{H}_{2}$ breath test with $25 \mathrm{~g}$ fructose are defined as moderate symptomatic fructose malabsorbers, whereas patients showing pathologic results in both $\mathrm{H}_{2}$ breath tests are classified as severe symptomatic fructose malabsorbers.

\section{Glucose hydrogen breath test}

An early pathologic increase in hydrogen levels $(\geq 20 \mathrm{ppm}$ above baseline during the first 60 minutes of the measurement period) in both lactose and fructose breath tests is suggestive of SIBO. Patients with suspected SIBO underwent the additional breath test with $50 \mathrm{~g}$ of glucose in $200 \mathrm{~mL}$ water.

\section{Upper endoscopy}

Patients with positive fructose and lactose breath tests are suggestive for celiac disease that often presents with secondary carbohydrate malabsorption due to duodenal atrophy. Therefore, these patients were asked to undergo upper endoscopy with duodenal biopsies.

\section{Statistical Methods}

Data are expressed as mean \pm SEM and analyzed by ANOVA followed by all pair-wise multiple comparison procedures (Tukey's 
post hoc test); $P<0.05$ was considered significant.

\section{Results}

\section{Study Population}

Overall, 2,390 patients with unclear abdominal discomfort performed both $\mathrm{H}_{2}$ breath tests with $50 \mathrm{~g}$ lactose and with $50 \mathrm{~g}$ fructose. Of these, 1,548 were female and 806 were male. The mean age was 49.6 years. The majority of patients was Caucasian $(\mathrm{n}=2,132)$, followed by Arabians $(\mathrm{n}=128)$, Mediterraneans ( $\mathrm{n}$ $=116)$, Asians $(\mathrm{n}=12)$ and Africans $(\mathrm{n}=1)$.

\section{Prevalence of Carbohydrate Malabsorption}

In the $\mathrm{H}_{2}$ breath test with $50 \mathrm{~g}$ lactose, 1,023/2,390 patients showed a significant $\mathrm{H}_{2}$ increase corresponding to a prevalence of lactose malabsorption of $42.8 \%$. Of these, 848 patients additionally reported abdominal symptoms, indicating a prevalence of lactose intolerance of $35.5 \%$ of the whole study population. Of these, 554 were female and 294 were male. Additionally, 365 patients reported symptoms although no $\mathrm{H}_{2}$ increase was seen, while in contrast, 175 patients showed an $\mathrm{H}_{2}$ increase but reported no symptoms (Table 1). Of the 848 symptomatic lactose malabsorbers, $679(80.1 \%)$ were of Caucasian, 93 (11.0\%) of Arabic, 65 (7.7\%) of Mediterranean and 11 (1.3\%) of Asian origin. The one African reported symptoms but did not have a corresponding $\mathrm{H}_{2}$ increase. On the contrary, the prevalence of symptomatic lactose malabsorption according to ethnicity was $91.7 \%$ in the Asian population, $72.7 \%$ in the Arabian, $56 \%$ in the Mediterranean, and

Table 1. Prevalence of Symptomatic Lactose and Fructose Malabsorption

\begin{tabular}{|c|c|c|c|}
\hline Breath test & $\begin{array}{c}\text { Lactose } \\
(50 \mathrm{~g})\end{array}$ & $\begin{array}{l}\text { Fructose } \\
\text { (50 g) }\end{array}$ & $\begin{array}{c}\text { Fructose } \\
(25 \mathrm{~g})\end{array}$ \\
\hline Performed & 2,390 & 2,390 & 552 \\
\hline Abdominal overall & 1,213 & 1,703 & 267 \\
\hline \multirow{2}{*}{$\begin{array}{l}\text { Abdominal } \\
\text { symptoms }\end{array}$} & 365 & 172 & 97 \\
\hline & 848 & 1,531 & 170 \\
\hline \multirow[t]{2}{*}{$\mathrm{H}_{2}$ increase } & 1,023 & 1,818 & 226 \\
\hline & 175 & 287 & 56 \\
\hline
\end{tabular}

$\mathrm{H}_{2}$, hydrogen.

Data are presented as number of patients.
$31.8 \%$ in the Caucasian population, respectively.

In the breath test with $50 \mathrm{~g}$ fructose $1,818 / 2,390$ patients had a significant $\mathrm{H}_{2}$ increase, which translates into a prevalence of fructose malabsorption of $76.1 \%$. Of these, 1,531 patients were symptomatic fructose malabsorbers and reported abdominal symptoms indicating a prevalence of moderate symptomatic fructose malabsorption of $64 \%$ of the whole study population. Another 172 patients reported abdominal symptoms but had no $\mathrm{H}_{2}$ increase, while in contrast, 287 patients showed an $\mathrm{H}_{2}$ increase but reported no symptoms (Table 1). Of the 1,531 symptomatic fructose malabsorbers, 1,367 were of Caucasian, 82 of Arabic, 74 of Mediterranean, 7 of Asian and 1 of African origin.

The prevalence of symptomatic fructose malabsorption according to ethnicity was $64.1 \%$ in the Arabian and Caucasian, $63.8 \%$ in the Mediterranean and $58.3 \%$ in the Asian population, respectively.

Of all patients, 829 subjects showed a significant increase in both $\mathrm{H}_{2}$ breath tests. Of those, 587 additionally reported symptoms corresponding to a prevalence of combined symptomatic carbohydrate malabsorption of $25 \%$ of the whole study population.

\section{Severity of Symptomatic Fructose Malabsorption}

To assess the severity of fructose malabsorption, in case of a pathologic $\mathrm{H}_{2}$ breath test with $50 \mathrm{~g}$ fructose $(\mathrm{n}=1,818)$ an additional $\mathrm{H}_{2}$ breath test with $25 \mathrm{~g}$ fructose was conducted (Table 1). This breath test was performed in 552 patients. Of these, $226 \mathrm{pa}-$ tients had a significant $\mathrm{H}_{2}$ increase. Of these, 170 patients reported abdominal symptoms, thus defined as severe symptomatic fructose malabsorbers. Abdominal symptoms without $\mathrm{H}_{2}$ increase were reported by another 97 patients, while in contrast, 56 patients showed an $\mathrm{H}_{2}$ increase but reported no symptoms.

\section{Correlation of Maximal $\mathrm{H}_{2}$ Increase and Severity of Fructose Malabsorption}

The comparison of maximal $\mathrm{H}_{2}$ concentrations in the $\mathrm{H}_{2}$ breath test with $50 \mathrm{~g}$ fructose showed that patients with pathologic $\mathrm{H}_{2}$ breath test with $25 \mathrm{~g}$ fructose, classified as severe fructose malabsorbers, exhaled significantly higher $\mathrm{H}_{2}$ concentrations than patients with negative $\mathrm{H}_{2}$ breath test with $25 \mathrm{~g}$ fructose, defined as moderate fructose malabsorbers $(123.6 \pm 4.9$ vs. $90.1 \pm 2.9$ ppm, $P<0.001)$.

\section{Small Intestinal Bacterial Overgrowth}

In $460 / 659$ patients with early $\mathrm{H}_{2}$ increase in the fructose and 
Table 2. $\mathrm{H}_{2}$ Breath Test for Small Intestinal Bacterial Overgrowth (Glucose)

\begin{tabular}{lr}
\hline \multicolumn{2}{c}{ Glucose $(50 \mathrm{~g})$} \\
\hline Performed $(\mathrm{N})$ & 460 \\
Abdominal symptoms overall & 123 \\
Abdominal symptoms without $\mathrm{H}_{2}$ increase & 44 \\
Abdominal symptoms with $\mathrm{H}_{2}$ increase & 61 \\
$\mathrm{H}_{2}$ increase overall & 88 \\
$\mathrm{H}_{2}$ increase without abdominal symptoms & 17 \\
$\mathrm{No}_{2}$ increase, no abdominal symptoms & 277 \\
Early $\mathrm{H}_{2}$ increase (SIBO) & 85 \\
Late $\mathrm{H}_{2}$ increase (Dysbiosis of the terminal ileum) & 3 \\
\hline
\end{tabular}

Patients with early significant hydrogen $\left(\mathrm{H}_{2}\right)$ increase in the fructose and lactose test $(\mathrm{n}=659)$ were asked to take the glucose breath test to exclude small intestinal bacterial overgrowth (SIBO).

Data are presented as number of patients.

lactose breath test, a $\mathrm{H}_{2}$ breath test with $50 \mathrm{~g}$ glucose was performed (Table 2). A significant $\mathrm{H}_{2}$ increase, indicative of bacterial overgrowth was detected in 88 patients. A total of 123 patients indicated abdominal symptoms. In this subgroup 44 patients did not show a significant $\mathrm{H}_{2}$ increase, whereas 61 patients had a significant $\mathrm{H}_{2}$ increase. Of all 88 patients with significant $\mathrm{H}_{2}$ increase, 85 showed an early $\mathrm{H}_{2}$ increase, which is indicative of SIBO. Three patients had a late increase indicative of terminal ileum dysbiosis. The comparison of age between patients with positive and negative glucose breath test indicated that patients with positive glucose breath test were significantly older than patients with negative test $(54.8 \pm 1.8$ vs. $49.4 \pm 0.8$ years, $P<0.01)$.

\section{Prevalence of Other Gastrointestinal Pathologies}

Of all combined carbohydrate malabsorbers ( $\mathrm{n}=829), 161$ patients underwent upper endoscopy with duodenal biopsies. Of these, one was identified to have celiac disease and one had a duodenal ulcer. Neither gastric ulcer nor Whipple's disease were detected.

\section{Discussion}

In patients of mainly Caucasian origin with unclear abdominal discomfort the prevalence of symptomatic lactose and fructose malabsorption was $35 \%$ and $64 \%$, respectively. A combined lactose and fructose carbohydrate malabsorption was found in $25 \%$. To our knowledge, this study investigates for the first time the prevalence of carbohydrate malabsorption in such a large collec- tive of patients with IBS-like symptoms. The prevalence of symptomatic fructose malabsorption was similar $(\sim 60 \%)$ in the different ethnic groups while lactose malabsorption is differentially distributed throughout the different ethnic groups (Asian > Arabian $>$ Mediterranean $>$ Caucasian).

Böhmer and Tuynman ${ }^{22}$ found $24 \%$ of IBS patients to be lactose malabsorbers and Hamm et $\mathrm{al}^{23}$ diagnosed $23 \%$ lactose malabsorbers in a collective of 1,122 IBS patients. Hamm et $\mathrm{al}^{23}$ estimated $25 \%$ of the European and United States population to suffer from lactase deficiency. In our study 1,023/2,390 patients (43\%) had increase in $\mathrm{H}_{2}$ levels after the lactose breath test and were thus referred to as lactose malabsorbers. Of these, 848 additionally experienced abdominal symptoms during the test and were thus symptomatic lactose malabsorbers corresponding to a prevalence of $35 \%$ in our patient collective. It can be stated that we observed a higher prevalence of symptomatic lactose malabsorption than reported before in the literature. We thus assume that lactose indigestion is a frequent condition in patients with IBS-like symptoms. A heterogeneous patient collective consisting of ethnic groups with higher prevalence of lactose malabsorption (e.g., African or Mediterranean origin) could explain these findings but our patient collective consisted predominantly of Caucasians and $80 \%$ of the symptomatic lactose malabsorbers were of Caucasian origin. The prevalence of symptomatic lactose malabsorption according to ethnicity followed a characteristic distribution pattern and showed the highest prevalence in Asians, followed by Arabians, Mediterraneans and Caucasians. However, our patient collective was comprised of 2 times more females than males, and $65 \%$ of the symptomatic lactose malabsorbers were female which is consistent with other studies. ${ }^{24,25}$ Supported by the study of Erminia et $\mathrm{al}^{25}$ who reported a higher prevalence of symptomatic lactose malabsorption in women than men, the question remains whether and why more females suffer from lactose indigestion.

Farup et $\mathrm{al}^{26}$ examined a collective of IBS patients and healthy volunteers in Norway and found in both groups an approximate percentage of $4 \%$ to suffer from lactose malabsorption. Interestingly, about 6-fold more patients experienced symptoms during or after the lactose breath test, ${ }^{26}$ although no $\mathrm{H}_{2}$ increase was seen. In our study 365/2,390 (15\%) patients complained of symptoms during or after the test without $\mathrm{H}_{2}$ increase. The 3-hour lactose test duration was essentially based on the study by Casellas and Malagelada ${ }^{27}$ who showed that the lactose test could be shortened to 3 hours without loss of sensitivity and specificity, when a high dose of lactose is used. However, there is a chance of false 
negativity and symptomatic patients without $\mathrm{H}_{2}$ increase within 3 hours could have prolonged the test time to reveal a later $\mathrm{H}_{2}$ increase. Furthermore, parallel methane analysis has been reported to enhance sensitivity of breath tests and reduce the rate of false negative results, ${ }^{28,29}$ but was not performed in our study.

Since 1978, when elimination of fructose was first shown to relieve symptoms in patients suffering from abdominal discomfort $^{30}$ the role of fructose malabsorption in the genesis of IBS-like symptoms has received more attention. In a retrospective analysis of patients with IBS and fructose malabsorption on a low-fructose/fructan diet, ${ }^{31} 74 \%$ of patients reported symptomatic improvement on this dietary regimen. In a follow-up, randomized, placebo-controlled rechallenge trial in patients with IBS with fructose malabsorption ${ }^{32}$ all patients improved on a low-fructose/fructan diet, with significant exacerbation of symptoms by rechallenge of fructose or fructans. Since the 1970's the consumption of fructose has risen 1,000-fold and has approached levels at which malabsorption is even seen in healthy adults in which incomplete absorption of free fructose induces IBS-like symptoms that are often less severe and less frequent. ${ }^{33}$ In line with this finding, Beyer et $\mathrm{al}^{34}$ showed that $50 \%$ of healthy subjects suffered from gastrointestinal symptoms after a fructose load of $25 \mathrm{~g}$. Furthermore, sorbitol-containing food products have increased in popularity and sorbitol is often used in lower calorie foods and sugar-free chewing gum since it does not require insulin for metabolism and has fewer calories than glucose. Yet, fructose is one of sorbitol's metabolic by-products. Heavy consumers of diet products or fructose-sweetened beverages may consume between $60 \mathrm{~g}$ and $100 \mathrm{~g}$ fructose daily. ${ }^{35}$ A large serving size of common popular carbonated non-alcoholic beverages (700 $\mathrm{mL}$ ) contains as much as $43 \mathrm{~g}$ of fructose. Therefore, it is quite common that one consumes more than $25 \mathrm{~g}$ of fructose with one meal and testing patients with $50 \mathrm{~g}$ fructose is thus not an unrealistic load. However, some might consider such a dose too high with the rational that every person develops abdominal symptoms at this dose but it has to be taken into account that fructose doses of less than $50 \mathrm{~g}$ show false negative results in part of the patients with fructose malabsorption. ${ }^{10}$ In addition, 19-29\% of test persons do neither develop symptoms nor produce excessive hydrogen upon ingestion of $50 \mathrm{~g}$ fructose since all studies that used $50 \mathrm{~g}$ fructose reported a prevalence of fructose malabsorption of $71-81 \% .^{10,35-39}$ In our collective of 2,390 patients with IBS-like symptoms, $17 \%$ did neither develop symptoms nor have an increase in $\mathrm{H}_{2}$ levels after a $50 \mathrm{~g}$ fructose load which corroborates former findings of smaller patient collectives. However,
$64 \%$ suffered from symptomatic fructose malabsorption. The present study is in line with former results by Choi et $\mathrm{al}^{10}$ who observed $73 \%$ fructose malabsorption in patients $(n=183,50 \mathrm{~g} / 150$ $\mathrm{mL}$ water, fructose concentration of $33 \%$ ) with unexplained $\mathrm{ab}-$ dominal symptoms. Moreover, a prevalence of $44 \%$ for fructose malabsorption and $73 \%$ for fructose-sorbitol malabsorption was described in a collective of patients with unclear functional complaints or diagnosed with IBS. ${ }^{40}$ Both, test dose and concentration seem to be important for the hydrogen increase. Choi et $\mathrm{al}^{10}$ found an increasing prevalence of fructose malabsorption of 39\%, 70\% and $80 \%$ with test concentrations of $10 \%, 20 \%$ and $30 \%$ (with 50 $\mathrm{g}$ fructose each), respectively. In our study we used $50 \mathrm{~g} / 200 \mathrm{~mL}$ and $25 \mathrm{~g} / 100 \mathrm{~mL}$ which correspond to a fructose concentration of $25 \%$ in both tests. Thus, the fact that we found a higher prevalence of fructose malabsorption with $50 \mathrm{~g}$ compared to $25 \mathrm{~g}$ is not a result of the concentration ( $25 \%$ in both) but rather the test dose.

In our study, patients that were symptomatic moderate fructose malabsorbers with a $50 \mathrm{~g}$ load $(\mathrm{n}=1,531)$ were asked to undergo a fructose breath test with $25 \mathrm{~g}$ of fructose $(\mathrm{n}=557)$. Of these, 170 responded positively and were thus referred to as severe symptomatic fructose malabsorbers. Interestingly, patients that were severe fructose malabsorbers showed higher end-expiratory hydrogen levels with the $50 \mathrm{~g}$ load compared to the moderate fructose malabsorbers. Whether these patients would thus benefit more from a stricter dietary approach remains to be investigated.

The term "intolerance" may be misleading. In our study we use the term malabsorption instead. The positive result of a breath test alone does not render a person intolerant to the respective sugar. In clinical routine, patients with a positive breath test should undergo elimination diet to determine the relevance of the breath test result in daily life. Only if symptoms disappear during a lactose or fructose free diet they could be considered as being intolerant. However, some patients have negative test results but suffer from gastrointestinal symptoms every time they consume lactose containing food products. This group should be considered intolerant as well-even without test. Taken together, not just test results but food diaries and outcome of an elimination diet define food intolerance.

SIBO is characterized by abnormally high bacterial population levels in the small intestine. IBS-like symptoms such as pain, bloating or diarrhea can be found in SIBO. Due to the non-invasiveness, low costs and good sensitivity compared to jejunal culture, breath tests are becoming more popular ${ }^{41,42}$ in the diagnosis of SIBO. In our study 88/460 subjects had a positive 
glucose breath test indicative of SIBO. Furthermore, we confirmed a correlation of SIBO with age which has been extensively described before. ${ }^{43,44}$ Malnutrition in the elderly has been discussed as a cause for malabsorption making the bowel more susceptible for bacterial overgrowth. ${ }^{43,45}$ Furthermore, hypochlorhydria, impaired peristalsis, duodenal diverticula and previous gastrointestinal surgery have been mentioned as possible causes for intestinal malabsorption. ${ }^{43}$ In the present retrospective trial, our patient collective was not evaluated concerning these co-morbidities.

Recently, other studies detected that SIBO is a frequent condition in therapy refractory patients with celiac disease ${ }^{46-48}$ rendering a glucose breath test in celiac patients helpful. Pironti et $\mathrm{al}^{24}$ concluded in their study that routine duodenal biopsies could be helpful in revealing abnormalities in patients with chronic diarrhea and/or abdominal pain. In our patient collective, 161 patients with combined carbohydrate malabsorption underwent upper endoscopy with duodenal biopsies. However, only one patient with celiac disease was detected indicating that it very rarely underlies the combined carbohydrate malabsorption.

According to a recent meta-analysis, the current IBS prevalence is $11 \%$ worldwide $^{49}$ and management of the disease is challenging. It is noteworthy that patients suffering from carbohydrate malabsorption can present with IBS-like symptoms and are often misdiagnosed with IBS. Thus, it is worth to exclude well-treatable conditions such as symptomatic carbohydrate malabsorption before confronting patients with the diagnosis of IBS. Although current German, British and American guidelines discuss a role for carbohydrate malabsorption in IBS, they do not specifically recommend both, fructose and lactose breath tests prior to the diagnosis. ${ }^{50-52}$ Since most patients with carbohydrate malabsorption benefit from an elimination diet, this condition can be easily treated.

In conclusion, in our collective of 2,390 patients with unexplained gastrointestinal symptoms with otherwise unremarkable clinical findings and in the absence of red flag signs, roughly one third were symptomatic lactose malabsorbers and two thirds symptomatic fructose malabsorbers, respectively. One quarter of patients had a combined symptomatic carbohydrate malabsorption. Thus, given the high prevalence of carbohydrate malabsorption in patients with unexplained gastrointestinal discomfort or pain, $\mathrm{H}_{2}$ breath tests to detect lactose and/or fructose malabsorption are recommended in the diagnostic workup of these patients.

\section{References}

1. Swagerty DL Jr, Walling AD, Klein RM. Lactose intolerance. Am Fam Physician 2002;65:1845-1850.

2. Wasserman D, Hoekstra JH, Tolia V, et al. Molecular analysis of the fructose transporter gene (GLUT5) in isolated fructose malabsorption. J Clin Invest 1996;98:2398-2402.

3. Romagnuolo J, Schiller D, Bailey RJ. Using breath tests wisely in a gastroenterology practice: an evidence-based review of indications and pitfalls in interpretation. Am J Gastroenterol 2002;97:1113-1126.

4. Keller J, Franke A, Storr M, Wiedbrauck F, Schirra J. [Clinically relevant breath tests in gastroenterological diagnostics -recommendations of the German society for neurogastroenterology and motility as well as the German society for digestive and metabolic diseases]. Z Gastroenterol 2005;43:1071-1090. [German]

5. Riby JE, Fujisawa T, Kretchmer N. Fructose absorption. Am J Clin Nutr 1993;58(suppl):748S-753S.

6. Southgate DA. Digestion and metabolism of sugars. Am J Clin Nutr 1995;62(suppl):203S-210S; discussion 211S.

7. Simrén M, Stotzer PO. Use and abuse of hydrogen breath tests. Gut 2006;55:297-303.

8. Stone-Dorshow T, Levitt MD. Gaseous response to ingestion of a poorly absorbed fructo-oligosaccharide sweetener. Am J Clin Nutr 1987;46:61-65.

9. Fernández-Bañares F, Esteve-Pardo M, de Leon R, et al. Sugar malabsorption in functional bowel disease: clinical implications. Am J Gastroenterol 1993;88:2044-2050.

10. Choi YK, Johlin FC, Jr, Summers RW, Jackson M, Rao SS. Fructose intolerance: an under-recognized problem. Am J Gastroenterol 2003;98:1348-1353.

11. Scrimshaw NS, Murray EB. The acceptability of milk and milk products in populations with a high prevalence of lactose intolerance. Am J Clin Nutr 1988;48(suppl):1079-1159.

12. Gudmand-Hoyer E. The clinical significance of disaccharide maldigestion. Am J Clin Nutr 1994;59(suppl):735S-741S.

13. Rosenkranz W, Hadorn B, Muller W, Heinz-Erian P, Hensen C, Flatz G. Distribution of human adult lactase phenotypes in the population of Austria. Hum Genet 1982;62:158-161.

14. Zhu Y, Zheng X, Cong Y, et al. Bloating and distention in irritable bowel syndrome: the role of gas production and visceral sensation after lactose ingestion in a population with lactase deficiency. Am J Gastroenterol 2013;108:1516-1525.

15. O'Keefe SJ, Adam JK. Primary lactose intolerance in Zulu adults. S Afr Med J 1983;63:778-780.

16. Suarez FL, Savaiano DA, Levitt MD. A comparison of symptoms after the consumption of milk or lactose-hydrolyzed milk by people with self-reported severe lactose intolerance. N Engl J Med 1995;333:1-4.

17. Böhmer CJ, Tuynman HA. The clinical relevance of lactose malabsorption in irritable bowel syndrome. Eur J Gastroenterol Hepatol 1996;8:1013-1016.

18. Mishkin D, Sablauskas L, Yalovsky M, Mishkin S. Fructose and sorbitol malabsorption in ambulatory patients with functional dyspepsia: comparison with lactose maldigestion/malabsorption. Dig Dis Sci 1997;42:2591-2598. 
19. Gibson PR, Shepherd SJ. Evidence-based dietary management of functional gastrointestinal symptoms: the FODMAP approach. J Gastroenterol Hepatol 2010;25:252-258.

20. Barrett JS, Gibson PR. Fermentable oligosaccharides, disaccharides, monosaccharides and polyols (FODMAPs) and nonallergic food intolerance: FODMAPs or food chemicals? Therap Adv Gastroenterol 2012;5:261-268.

21. Riedl A, Maass J, Fliege H, et al. Subjective theories of illness and clinical and psychological outcomes in patients with irritable bowel syndrome. J Psychosom Res 2009;67:449-455.

22. Böhmer CJ, Tuynman HA. The effect of a lactose-restricted diet in patients with a positive lactose tolerance test, earlier diagnosed as irritable bowel syndrome: a 5-year follow-up study. Eur J Gastroenterol Hepatol 2001;13:941-944.

23. Hamm LR, Sorrells SC, Harding JP, et al. Additional investigations fail to alter the diagnosis of irritable bowel syndrome in subjects fulfilling the Rome criteria. Am J Gastroenterol 1999;94:1279-1282.

24. Pironti A, Tadeu V, Pedroni A, et al. Role of routine small intestinal biopsy in adult patient with irritable bowel syndrome-like symptoms. Minerva Med 2010;101:129-134.

25. Erminia R, Ilaria B, Tiziana M, et al. HRQoL questionnaire evaluation in lactose intolerant patients with adverse reactions to foods. Intern Emerg Med 2013;8:493-496.

26. Farup PG, Monsbakken KW, Vandvik PO. Lactose malabsorption in a population with irritable bowel syndrome: prevalence and symptoms. A case-control study. Scand J Gastroenterol 2004;39: 645-649.

27. Casellas F, Malagelada JR. Applicability of short hydrogen breath test for screening of lactose malabsorption. Dig Dis Sci 2003;48: 1333-1338.

28. Corazza GR, Benati G, Strocchi A, Malservisi S, Gasbarrini G. The possible role of breath methane measurement in detecting carbohydrate malabsorption. J Lab Clin Med 1994;124:695-700.

29. de Lacy Costello BP, Ledochowski M, Ratcliffe NM. The importance of methane breath testing: a review. J Breath Res 2013;7: 024001.

30. Andersson DE, Nygren A. Four cases of long-standing diarrhoea and colic pains cured by fructose-free diet-a pathogenetic discussion. Acta Med Scand 1978;203:87-92.

31. Shepherd SJ, Gibson PR. Fructose malabsorption and symptoms of irritable bowel syndrome: guidelines for effective dietary management. J Am Diet Assoc 2006;106:1631-1639.

32. Shepherd SJ, Parker FC, Muir JG, Gibson PR. Dietary triggers of abdominal symptoms in patients with irritable bowel syndrome: randomized placebo-controlled evidence. Clin Gastroenterol Hepatol 2008;6:765-771.

33. Gibson PR, Newnham E, Barrett JS, Shepherd SJ, Muir JG. Review article: fructose malabsorption and the bigger picture. Aliment Pharmacol Ther 2007;25:349-363.

34. Beyer PL, Caviar EM, McCallum RW. Fructose intake at current levels in the United States may cause gastrointestinal distress in normal adults. J Am Diet Assoc 2005;105:1559-1566.

35. Perman JA. Digestion and absorption of fruit juice carbohydrates. J
Am Coll Nutr 1996;15(suppl):12S-17S.

36. Ravich WJ, Bayless TM, Thomas M. Fructose: incomplete intestinal absorption in humans. Gastroenterology 1983;84:26-29.

37. Rumessen JJ, Gudmand-Hoyer E. Absorption capacity of fructose in healthy adults. Comparison with sucrose and its constituent monosaccharides. Gut 1986;27:1161-1168.

38. Ladas SD, Grammenos I, Tassios PS, Raptis SA. Coincidental malabsorption of lactose, fructose, and sorbitol ingested at low doses is not common in normal adults. Dig Dis Sci 2000;45:2357-2362.

39. Johlin FC Jr, Panther M, Kraft N. Dietary fructose intolerance: diet modification can impact self-rated health and symptom control. Nutr Clin Care 2004;7:92-97.

40. Goldstein R, Braverman D, Stankiewicz H. Carbohydrate malabsorption and the effect of dietary restriction on symptoms of irritable bowel syndrome and functional bowel complaints. Isr Med Assoc J 2000;2:583-587.

41. Kerlin P, Wong L. Breath hydrogen testing in bacterial overgrowth of the small intestine. Gastroenterology 1988;95:982-988.

42. Kaye SA, Lim SG, Taylor M, Patel S, Gillespie S, Black CM. Small bowel bacterial overgrowth in systemic sclerosis: detection using direct and indirect methods and treatment outcome. Br J Rheumatol 1995;34:265-269.

43. McEvoy A, Dutton J, James OF. Bacterial contamination of the small intestine is an important cause of occult malabsorption in the elderly. Br Med J (Clin Res Ed) 1983;287:789-793.

44. Lewis SJ, Potts LF, Malhotra R, Mountford R. Small bowel bacterial overgrowth in subjects living in residential care homes. Age Ageing 1999;28:181-185.

45. Gracey MS. Nutrition, bacteria and the gut. Br Med Bull 1981;37: 71-75.

46. Fine KD, Meyer RL, Lee EL. The prevalence and causes of chronic diarrhea in patients with celiac sprue treated with a gluten-free diet. Gastroenterology 1997;112:1830-1838.

47. Tursi A, Brandimarte G, Giorgetti G. High prevalence of small intestinal bacterial overgrowth in celiac patients with persistence of gastrointestinal symptoms after gluten withdrawal. Am J Gastroenterol 2003;98:839-843.

48. Ghoshal UC, Ghoshal U, Misra A, Choudhuri G. Partially responsive celiac disease resulting from small intestinal bacterial overgrowth and lactose intolerance. BMC Gastroenterol 2004;4:10.

49. Lovell RM, Ford AC. Global prevalence of and risk factors for irritable bowel syndrome: a meta-analysis. Clin Gastroenterol Hepatol 2012;10:712-721, e4.

50. Spiller R, Aziz Q, Creed F, et al. Guidelines on the irritable bowel syndrome: mechanisms and practical management. Gut 2007;56: 1770-1798.

51. Layer P, Andresen V, Pehl C, et al. [Irritable bowel syndrome: German consensus guidelines on definition, pathophysiology and management]. Z Gastroenterol 2011;49:237-293. [German]

52. Drossman DA, Camilleri M, Mayer EA, Whitehead WE. AGA technical review on irritable bowel syndrome. Gastroenterology 2002; 123:2108-2131. 